\title{
Wilderness medicine at high altitude: recent developments in the field
}

This article was published in the following Dove Press journal:

Open Access Journal of Sports Medicine

24 September 2015

Number of times this article has been viewed

\author{
Neeraj M Shah' \\ Sidra Hussain ${ }^{2}$ \\ Mark Cooke ${ }^{3}$ \\ John P O'Hara ${ }^{3}$ \\ Adrian Mellor 3,4 \\ 'Division of Asthma, Allergy and \\ Lung Biology, King's College London, \\ UK; ${ }^{2}$ School of Medicine, University \\ College London, London, UK; \\ ${ }^{3}$ Research Institute for Sport, Physical \\ Activity and Leisure, Leeds Beckett \\ University, Leeds, UK; ${ }^{4}$ Academic \\ Department of Military Anaesthesia \\ and Critical Care, Royal Centre for \\ Defence Medicine, Birmingham, UK
}

Correspondence: Neeraj M Shah 49 Bodley Road, New Malden, Surrey KT3 5QD, UK Tel +447739576 II5 Email neeraj.shah@nhs.net

\begin{abstract}
Travel to high altitude is increasingly popular. With this comes an increased incidence of high-altitude illness and therefore an increased need to improve our strategies to prevent and accurately diagnose these. In this review, we provide a summary of recent advances of relevance to practitioners who may be advising travelers to altitude. Although the Lake Louise Score is now widely used as a diagnostic tool for acute mountain sickness (AMS), increasing evidence questions the validity of doing so, and of considering AMS as a single condition. Biomarkers, such as brain natriuretic peptide, are likely correlating with pulmonary artery systolic pressure, thus potential markers of the development of altitude illness. Established drug treatments include acetazolamide, nifedipine, and dexamethasone. Drugs with a potential to reduce the risk of developing AMS include nitrate supplements, propagators of nitric oxide, and supplemental iron. The role of exercise in the development of altitude illness remains hotly debated, and it appears that the intensity of exercise is more important than the exercise itself. Finally, despite copious studies demonstrating the value of preacclimatization in reducing the risk of altitude illness and improving performance, an optimal protocol to preacclimatize an individual remains elusive.
\end{abstract}

Keywords: hypoxia, acute mountain sickness, acclimatization, biomarkers, preacclimatization

\section{Introduction}

Travel to high altitude is increasingly popular. In a 12-month period, UK-based commercial companies offered 93 expeditions to climb Mount Kilimanjaro (5,895 m) alone. ${ }^{1}$ With increasing popularity comes an increased incidence of high-altitude illness. It is not a problem at extreme altitude only; $25 \%$ of conference attendees at a medical conference in the Rocky Mountains, at elevations of $\sim 2,000 \mathrm{~m}$, reported symptoms attributable to acute mountain sickness (AMS). ${ }^{2}$ With $>120$ million people visiting the European Alps each year at similar altitudes, ${ }^{3}$ this is a significant public health problem.

In this review, we aim to summarize the recent advances in this field of relevance to sports and travel medicine practitioners who may be advising travelers to high altitude $(2,500-5,500 \mathrm{~m})$ or extreme altitude $(>5,500 \mathrm{~m})$. After summarizing the basic physiological changes that occur at high altitude and the illnesses that accompany them, we discuss some novel approaches to diagnosing and monitoring altitude illness. We then go on to discuss novel pharmacological treatments that may be of use and ways in which travelers may be able to prepare themselves to cope with high altitude.

\section{Adaptation to altitude}

With ascent to high altitude, barometric pressure and therefore the partial pressure of oxygen in inspired air fall. The atmospheric pressure at sea level is $760 \mathrm{mmHg}$, whereas 
at 5,500 $\mathrm{m}$ above sea level (the altitude of Everest Base Camp, a popular trekking destination), it is $380 \mathrm{mmHg}$. Halving the amount of oxygen in inspired air has profound effects on human physiology. In an unacclimatized individual, this will immediately result in breathlessness and reduced exercise tolerance. Arterial oxygen saturations may be $<80 \%,{ }^{4}$ and at extreme altitude, arterial oxygen saturations as low as $34 \%$ are recorded in healthy individuals. ${ }^{5}$

Acute exposure to such low oxygen tensions would cause unconsciousness within minutes, ${ }^{6}$ yet certain individuals are able to climb as high as the summit of Mount Everest ( $8,848 \mathrm{~m}$ ) without supplementary oxygen. The physiological changes that take place to adapt to this hypoxic environment are known as acclimatization. On immediate exposure, there is a rise in heart rate and respiratory rate followed by a diuresis, which decreases plasma volume (increasing hematocrit) and produces an acidemia secondary to bicarbonate excretion. To increase the oxygen-carrying capacity of the blood, hemoglobin production will increase and a rightward shift of the oxygen dissociation curve will alter the oxygen-binding capacity of hemoglobin. ${ }^{4}$ The physiological changes are highly individual and in a proportion of individuals, high-altitude illness may occur if they ascend to high altitude $(>3,500 \mathrm{~m})$ more quickly than their physiology adapts to the hypoxic conditions.

\section{High-altitude illnesses}

High-altitude illness present in various forms, all of which form a spectrum of disease, encompassing AMS, high-altitude pulmonary edema (HAPE), and high-altitude cerebral edema (HACE).

The most common illness is AMS. It is present in up to $75 \%$ of individuals on common trekking routes. ${ }^{7,8}$ Common symptoms include headache, nausea, fatigue, dizziness, anorexia, and sleep disturbance. Diagnosis of AMS is difficult as none of the symptoms are specific to it. Furthermore, no physiological variable has been validated to effectively detect the onset of AMS. The Lake Louise Score (LLS) was developed for research purposes to define AMS, ${ }^{9}$ using subjective, nonspecific symptoms. As there is no underlying mechanism to explain this collection of symptoms together, it is now less widely accepted that they be grouped together as one disease. ${ }^{10}$ The prevailing pragmatic approach to its management, however, is that if an individual is unwell with a headache at altitude, and no other cause can be found, they should be treated as having AMS. Management involves descent and simple analgesia, with the addition, in more severe cases, of supplemental oxygen, hyperbaric chamber, acetazolamide (a carbonic anhydrase inhibitor causing diuresis), and dexamethasone (a potent glucocorticoid that reduces symptoms).

Most deaths at high altitude are caused by HAPE. ${ }^{11}$ It occurs when intravascular fluid leaks out into the extravascular space, impeding gaseous exchange. It seems the most likely etiology is an exaggerated hypoxic pulmonary vasoconstrictive response, resulting in a raised pulmonary artery systolic pressure (PASP) and a subsequent transudative capillary leak. ${ }^{12}$ It tends to occur 2-4 days after arrival at high altitude, presenting initially with shortness of breath on exertion and deteriorating to shortness of breath at rest, accompanied by a wet cough, hemoptysis, orthopnea, chest pain, headache, and confusion. It is frequently associated with AMS or HACE. Management of HAPE involves rapid descent, supplemental oxygen, nifedipine (a dihydropyridine calcium channel blocker), or sildenafil to bring about pulmonary vasodilatation and the use of a hyperbaric chamber if descent is not possible. $^{4}$

HACE usually follows on from AMS. The mechanism underlying this is not clear, but the tight-fit hypothesis has been mooted as a possible explanation. This suggests that individuals with less compliant cerebrospinal fluid systems have a greater increase in intracranial pressure (ICP) for any given increase in brain volume, resulting from cerebral edema and leads to neurological compromise. Limited data have demonstrated a dramatic increase in ICP in individuals with AMS compared to those without, and this may support this theory. ${ }^{13,14}$ Although most cases are preceded by a prodrome of AMS-like symptoms, occasionally HACE can develop suddenly in previously fit individuals. ${ }^{15}$ Symptoms include headache, nausea, hallucination, disorientation, confusion, and reduced consciousness. Management includes rapid descent, supplemental oxygen, and dexamethasone.

Both HAPE and HACE are medical emergencies, and it is imperative that individuals suffering from these conditions are evacuated back down to a safer altitude straightaway. It is particularly important as although the medications discussed are evidence based and recommended in the most recent international guidelines on managing altitude illness, ${ }^{16}$ it appears that commercial operators do not routinely carry them. ${ }^{17}$ It is equally important, therefore, that we have reliable and accurate tools to predict and diagnose these conditions.

\section{Diagnosis of AMS Lake Louise Scoring system}

Despite its development as a research tool, the LLS is widely used to diagnose AMS. Headache must be present for the diagnosis of AMS with at least one other symptom 
(gastrointestinal symptoms, fatigue and/or weakness, dizziness, difficulty sleeping). Each symptom is scored from 0 (none) to 3 (severe). A total score of 3 or more in the presence of a headache is diagnostic for AMS. ${ }^{9}$ The use of this score has been validated in a recent normobaric hypoxia chamber study. ${ }^{18}$ Much has been published about the utility and value of headache being a discriminatory feature of AMS. The incidence of headache at altitude is up to $100 \%>4,500 \mathrm{~m} .{ }^{19}$ A survey on Mount Damavand reported that $87 \%$ of trekkers at high altitude suffer from a headache. ${ }^{20}$ Of these, $70 \%$ had other features suggestive of AMS. This suggests that $30 \%$ of trekkers have headache that is not related to AMS, questioning the validity of using headache as a compulsory feature of an AMS diagnosis. Other causes of headache at altitude can include dehydration, migraines, tension headaches, sinusitis, and frontal muscle contraction from sun glare. Headache pattern may be useful in AMS diagnosis; $100 \%$ of trekkers with an occipital headache and $83 \%$ of those with a temporal headache had other features of AMS. ${ }^{20}$ This is supported by a study measuring changes in cerebral hemodynamics after acute exposure to altitude, which demonstrated significantly greater blood flow in the posterior cerebral circulation in individuals suffering from AMS, compared with those without symptoms. ${ }^{21}$ It seems occipital or temporal headaches at high altitude are almost diagnostic for AMS, and there is, perhaps, a need for the headache of AMS to be characterized as such. The issue of whether headache should be afforded preponderance remains hotly debated. ${ }^{22,23}$ While the place of headache in the diagnosis of AMS is being debated, an algorithm has been developed for assessing individuals with headache at altitude, using a pragmatic approach, taking into account a past medical history of headache-associated illness and other features consistent with $\mathrm{AMS}^{24}$

The place of poor sleep quality in the diagnosis of AMS has also been questioned. A large symptomatology analysis using a novel correlation networks methodology demonstrated two clusters of symptoms, one with a preponderance of individuals with poor sleep quality and the other with headaches. ${ }^{10}$ Few individuals suffered from both headaches and poor sleep quality. Another study demonstrated a poor correlation between poor sleep quality and the other features of AMS, and that by eliminating sleep from the score, the repeatability of an AMS diagnosis was stronger. ${ }^{25}$

\section{Biomarkers}

Biomarkers can be useful tools to predict or diagnose highaltitude illness if demonstrated to be reliable and accurate. They may also have utility in tracking an individual's illness to assess satisfactory resolution following treatment. With the development of simple point-of-care diagnostic systems, these may have utility for diagnosis in the field.

The association between brain natriuretic peptide (BNP) and congestive cardiac failure has raised an interest in its use as a biomarker in both AMS and HAPE. It is a neurohormone, primarily secreted by cardiac ventricular myocytes in response to stretching, caused by fluid overload. Its release results in a reduction in systemic vascular resistance and central venous pressure and an increase in natriuresis; leading to a decrease in blood volume and systemic blood pressure, which in turn leads to an increase in cardiac output. ${ }^{26}$ Clinically, it rises in proportion to increasing severity of heart failure and is thus used as a marker of the extent of heart failure. As AMS is associated with fluid retention, ${ }^{27}$ it would lead to cardiac stretch and BNP release. Using point-of-care monitoring systems, Woods et al reported that elevated BNP levels are significantly correlated with severe AMS diagnosed using the LLS. ${ }^{28}$ As discussed earlier, elevated PASP is important in the development of HAPE. ${ }^{12}$ Elevated BNP levels are also associated with elevated PASP, ${ }^{29,30}$ and BNP reduces with improving symptoms once HAPE has been treated. ${ }^{31,32}$ All of these recent studies suggest that BNP may have value as biomarkers for HAPE and could have utility in prescreening individuals of risk, and more importantly, with the advent of point-of-care testing technology, diagnosing patients with HAPE. In the field, this may help to discriminate between a simple chest infection requiring antibiotics and HAPE requiring immediate evacuation.

Asymmetric dimethylarginine (ADMA), a nitric oxide synthase inhibitor, was investigated as a marker of PASP in a hypobaric chamber study. ${ }^{33}$ Although no relationship was demonstrated between elevated ADMA and PASP or AMS, a significant decrease in ADMA was correlated with AMS and PASP $>40 \mathrm{mmHg}$ (the threshold for diagnosing HAPE). Furthermore, the change in ADMA 2 hours after exposure to hypoxia was predictive for LLS $>5$. Much more work is needed to determine its validity; however, this study demonstrates that there may be potential for the use of ADMA as a predictive biomarker for AMS and HAPE.

Using the prevailing opinion that oxidative stress is a contributory factor to the development of high-altitude illness, ${ }^{4}$ work has been done on the potential of using markers of oxidative stress to predict or diagnose AMS. The levels of neutrophil gelatinase-associated lipocalin, a marker of oxidative stress in the lungs, increased during trekking expeditions to $>5,000 \mathrm{~m}$, is correlated with the severity of AMS. ${ }^{34}$ Carbonyl proteins, also markers for oxidative stress, 
increase in proportion to the severity of AMS.${ }^{35}$ Conversely, a proteomic analysis has suggested that individuals with AMS had higher expression of antioxidants than those without, questioning the presumed benefit of antioxidants in the protection against and management of AMS. The study concludes by speculating that this overexpression may be compensation for hypoxia-induced free radical species production. ${ }^{36}$

The picture with biomarkers of altitude illness is very complex; a proteomic analysis of plasma proteins in rats exposed to hypoxia has identified 25 proteins whose expression changed with hypoxia. ${ }^{37}$ Any of these may prove useful; however, the goal remains to find a marker of altitude illness for clinical use and acclimatization for research studies.

\section{Novel drug treatments for AMS}

Established drug treatments include acetazolamide, dexamethasone, and nifedipine. Acetazolamide is thought to be effective in treating AMS, creating an acidemia, increasing ventilation, and therefore, increasing the arterial oxygen content. ${ }^{38}$ Dexamethasone is effective at reducing edema and symptoms in HACE, just as it is in any other form of cerebral edema. Nifedipine is used in HAPE for its dilatory effect on the pulmonary vasculature; however, a recent study did not demonstrate any benefit over descent and supplemental oxygen in patients with HAPE. ${ }^{39}$ In addition to these established treatments, potential novel therapies have been suggested such as ibuprofen, nitrates, and intravenous (IV) iron supplementation.

\section{Ibuprofen}

Other than the tight-fit hypothesis previously discussed, other possible mechanisms causing high-altitude headache include activation of the trigeminovascular system by vasodilatation or inflammatory mediators ${ }^{40,41}$ or alteration in the blood-brain barrier by inflammatory mediators causing vasogenic edema. ${ }^{13}$ The central role of inflammation in these mechanisms has led to the interest in nonsteroidal anti-inflammatory medications such as ibuprofen.

A meta-analysis encompassing the only three randomized controlled trials (RCTs) in the literature comparing the effect of ibuprofen against placebo in high-altitude headache $^{42-44}$ demonstrated a significant improvement in LLS with ibuprofen over placebo. ${ }^{45}$ However, it is perhaps not surprising that compared to placebo, a known headache medication resulted in an improvement in any form of headache. A further RCT comparing ibuprofen with acetazolamide has demonstrated equivalent effects on the severity of AMS using LLS, ${ }^{46}$ further supporting the theory that inflammation plays a part in the development of AMS and, in particular, high-altitude headache. Based on these trials, the most recent international guidelines on treatment of acute altitude illness do not recommend the routine use of ibuprofen as prophylaxis against AMS. ${ }^{16}$

\section{Nitrates}

Nitric oxide (NO) regulates physiological processes in the human body, including vasodilation, immune function, platelet aggregation, glucose homeostasis, muscle contraction, and mitochondrial function. Emerging evidence suggests that NO also plays an important role in altitude acclimatization. Lowlanders exposed to altitude initially exhibit reduced concentrations of exhaled NO, with the magnitude of this decline associated with susceptibility to altitude illness. ${ }^{47}$ With acclimatization, lowlanders demonstrate an increase in NO production. ${ }^{48}$ The adaptive response to hypoxia is particularly prominent in Tibetans who have greater plasma nitrite concentrations, indicative of elevated whole-body NO production, ${ }^{49}$ and higher exhaled NO relative to lowlanders. ${ }^{50}$ This affords them unique physiological advantages that result in a remarkable capacity to cope with the challenges of hypoxia relative to lowlanders. Therefore, given the importance of NO during altitude acclimatization, it is tempting to speculate that interventions increasing NO availability, especially during acute (ie, prior to acclimatization) and chronic altitude exposure (ie, during acclimatization), may be advantageous.

One possible means of eliciting this effect is via dietary nitrate supplementation (ie, nitrate-rich beetroot juice). Nitrate ingestion has been shown to increase plasma concentrations of NO metabolites (nitrate and nitrite), ${ }^{51}$ reduce steady-state oxygen consumption, ${ }^{52}$ improve arterial and tissue oxygenation, ${ }^{53}$ enhance exercise tolerance, ${ }^{53-55}$ and improve performance, ${ }^{56}$ during acute normobaric hypoxia. Interestingly, under hypoxic conditions, nitrate supplementation in the form of beetroot juice resulted in faster muscle recovery and restored maximal oxidative ATP resynthesis and exercise tolerance to normoxic values, when compared to placebo..$^{54,57}$ The mechanisms underlying these effects are still under investigation, but may involve improved mitochondrial, ${ }^{58}$ and/or muscle contractile efficiency, ${ }^{59}$ and enhanced tissue blood flow/better matching of oxygen delivery to metabolic rate. ${ }^{60}$

It is the prevailing opinion that AMS is triggered by a fall in arterial oxygen saturation (ie, hypoxemia) subsequent to hypoxic exposure. ${ }^{61}$ Therefore, improved arterial oxygen saturation with nitrate ingestion may be expected to reduce 
the incidence of AMS. There was no difference in mean AMS scores between participants consuming nitrate-rich beetroot juice and a nitrate-free placebo during acute $\left(\sim 2\right.$ hours) exposure to extreme normobaric hypoxia $\left(\mathrm{FiO}_{2}\right.$ $11 \%, \sim 5,000 \mathrm{~m}) .{ }^{53}$ However, six out of ten individuals were diagnosed positive for AMS with placebo ingestion versus only four with the ingestion of nitrate-rich beetroot juice. It is possible that the potential for nitrate to attenuate AMS may become more pronounced during more prolonged ( $>2$ hours) or extreme hypoxic exposure (for example, a high-altitude expedition), though this is yet to be established.

Both sildenafil (a selective phosphodiesterase type 5 [PDE-5] inhibitor) and bosentan (a nonselective endothelinreceptor antagonist) have been mooted as potential treatments for AMS, due to their effect on prolonging the effect of NO. Sildenafil has been demonstrated to reduce PASP, increase oxygen delivery, and minimize the decrease in exercise capacity in both normobaric hypoxia and actual high altitude..$^{62}$ By dilating the pulmonary vascular bed, these drugs reduce the degree of hypoxic pulmonary vasoconstriction and consequent pulmonary hypertension, and therefore, the risk of HAPE. Theoretically, this could improve exercise tolerance under hypoxic conditions. Indeed, they have been demonstrated to improve arterial oxygen saturations in individuals exercising at altitude. ${ }^{63,64}$ However, trials have failed to demonstrate an improvement in exercise capacity ${ }^{63}$ or incidence of AMS and HAPE. ${ }^{65}$ In fact, higher rates of AMS were reported in individuals treated with sildenafil, compared to placebo. ${ }^{65}$ This may be because headache is a recognized side effect of sildenafil, thus increasing an individual's LLS. Therefore, although there appears to be an improvement in arterial oxygen saturation with these medications, there does not appear to be a consequent improvement in function.

\section{IV iron supplementation}

Supplemental iron has been demonstrated to reverse hypoxiainduced pulmonary hypertension, while iron depletion results in increased pulmonary artery pressure. ${ }^{66,67}$ The mechanism for this and its potential benefit in AMS are thought to be due to its effect on hypoxia-inducible transcription factors (HIF). Excess iron decreases the stability of HIF, while iron depletion increases its stability ${ }^{68,69}$ In hypoxic conditions, oxygen-dependent hydroxylase enzymes are unable to degrade HIF, so iron supplementation encourages the breakdown of HIF, as in normoxic conditions. This is significant as HIF is believed to coordinate the cellular inflammatory response to hypoxia. ${ }^{70}$
IV iron supplementation immediately prior to ascent to high altitude resulted in a significantly lower rise in AMS score from sea level to altitude, compared to IV saline. However, there was no significant difference in absolute AMS score at altitude between the two groups. ${ }^{70}$ Iron supplementation is an intriguing prospect in the prophylactic management of AMS; however, its feasibility on field expeditions is questionable. Oral iron supplemental is a possible alternative that needs more investigation.

\section{Exercise and AMS}

While the exact mechanism underlying high-altitude illness remains hotly debated, exercise has been suggested as an independent risk factor for the development of AMS. ${ }^{71}$ High-intensity intermittent exercise on a trekking expedition was associated with increased interstitial lung fluid at $4,090 \mathrm{~m},{ }^{72}$ suggesting that exercise increases the risk of HAPE Corroborating this, AMS scores were significantly higher in trekkers with higher rating of perceived exertion. ${ }^{73}$

Conversely, several recent chamber studies have failed to demonstrate a statistical difference in the development of AMS between rest and exercise at simulated altitude. ${ }^{74-76}$ Of note, in comparing the change in interstitial fluid between exercise in hypoxia at 4,090 $\mathrm{m}$ and exercise in simulated hypoxia, there was no significant increase in simulated hypoxia, while there was an increase in actual hypoxia. ${ }^{72}$ This suggests that chamber studies are possibly underestimating the effect of exercise on the development of AMS and HAPE, and that this may be due to the difference between the normobaric hypoxia experienced in chamber studies and hypobaric hypoxia experienced at altitude. $^{77}$

It has been hypothesized that exercise causes AMS by its effect on cortisol. AMS and HACE are fluid-retention states. Although high-altitude exposure tends to cause a marked diuresis and natriuresis, due to reduced aldosterone, numerous studies have reported an increase in cortisol at rest under hypoxic conditions. ${ }^{78}$ Exercise leads to a surge in cortisol levels at sea level, and so it has been hypothesized that by exercising at altitude, a large surge in cortisol is triggered, leading to fluid retention and possibly AMS. Cortisol levels measured in response to exercise did not demonstrate a significant increase at $4,270 \mathrm{~m}$, but did at $5,150 \mathrm{~m} .{ }^{78}$ Similarly, up to $3,750 \mathrm{~m}$, there was no significant increase in cortisol levels with exercise and no difference between hypoxia and normoxia. ${ }^{79}$ Exercise may also play a role in promoting a stress response involving arginine vasopressin, which would increase fluid retention. ${ }^{80}$ 
Increase in brain volume and cerebral edema have been reported in response to hypoxia in patients with AMS. .1,82 $^{8}$ A possible explanation for this is the cortisol surge seen in response to exercise; however, despite demonstrating an overall increase in white matter volume in response to hypoxia, there was no reported difference in the volume change between rest and exercise. ${ }^{76}$ There was also no relationship between development of AMS and change in cerebral volume. A study investigating the effect of exercise on markers of oxidative stress in normobaric hypoxia demonstrated that moderate-intensity exercise reduces oxidative stress, suggesting that exercise is protective against AMS, not causative. ${ }^{83}$

From the information presented earlier, it appears that the role of exercise may be complex and related to intensity of exercise rather than undertaking any exercise.

\section{Is preacclimatization helpful?}

Altitude acclimatization is a series of physiological responses that compensate for the reduction in the partial pressure of oxygen with increasing altitude. ${ }^{84}$ If acclimatization is inadequate, the frequency and severity of illnesses such as AMS increases. ${ }^{85}$ Continuous exposure to terrestrial altitudes $>3,000 \mathrm{~m}$ reduces the susceptibility to AMS at very high altitudes $(>3,500 \mathrm{~m})^{86}$ and improves the exercise performance. ${ }^{87}$ However, it is not always feasible to spend time at high altitude before an expedition. Acclimation (or preacclimatization) describes the physiological responses associated with acclimatization but as a result of techniques other than continuous exposure to terrestrial altitude. ${ }^{88}$ Intermittent hypoxic exposure (IHE) is passive exposure to hypoxia lasting from seconds to hours that is repeated over several days to weeks, ${ }^{89}$ interspersed with normoxia. Intermittent hypoxic training (IHT) is the use of intermittent hypoxia with periods of exercise.

There are two key papers that underpin the evidence for use of preacclimatization. Richalet et $\mathrm{a}^{90}$ used an acclimation protocol that comprised of a 1-week sojourn on Mont Blanc (between 4,350 $\mathrm{m}$ and 4,807 $\mathrm{m}$ ) and then 4 days of IHE (from 5,000 $\mathrm{m}$ to $8,500 \mathrm{~m}$ ) in a hypobaric chamber ( $\sim 10$ hours per day, total of 38 hours). This resulted in a $12 \%$ increase in hemoglobin and a $7 \%$ increase in arterial oxygen saturation $\left(\mathrm{SaO}_{2}\right)(75 \% \pm 4 \%-82 \% \pm 3 \%)$ during submaximal exercise $\left(70 \%\right.$ of $\left.\mathrm{VO}_{2 \max }\right)$ in normobaric hypoxia $\left(\mathrm{FIO}_{2}=0.115, \sim 4,800 \mathrm{~m}\right)$. Climbers subsequently reached $7,800 \mathrm{~m}$ only 5 days after leaving base camp, gaining $5,600 \mathrm{~m}$ in only 6 days. Conventional expeditions would reach the same altitude in 12-32 days. A similar study using continuous preacclimatization on Mont Blanc and IHE in a hypobaric chamber induced sufficient adaptation to allow rapid progression to extreme altitude, saving 1-2 weeks of acclimatization. ${ }^{88}$

In terms of the hematological adaptations associated with acclimation, there is conflicting evidence, with some studies reporting no significant erythropoetic effect as a result of IHE, ${ }^{91,92}$ while others have shown significant increases in both red blood cell count and hemoglobin $(10.8 \%-12 \%) .{ }^{93-95}$ This may be due to differences in the magnitude of hypoxic stimulus (duration, frequency, and number of exposures), as well as the difference in physiological responses documented, ${ }^{96-98}$ between hypobaric- and normobaric-simulated altitudes. Comparisons between modes of hypoxic stimulus show that there are very few normobaric hypoxic studies that have produced significant hematological adaptations. ${ }^{99}$ In contrast, there is greater consistency in the reported improvements in hypoxic ventilatory response, using both normobaric ${ }^{100,101}$ and hypobaric chambers, ${ }^{102,103}$ though hypobaricity seems to be consistently more effective. With regard to exercise performance, Beidleman et al have conducted many studies, ${ }^{85,86,104-106}$ using various methodologies from 1 week $^{106}$ to 3 weeks, ${ }^{104}$ on IHE (hypobaric, 4,300 m), reporting significant improvements in cycle time-trial performance (16\%-21\%). However, they also reported no significant changes in cycle time-trial performance at 4,300 $\mathrm{m}$ following 7 days of normobaric IHE at 4,500 m. ${ }^{105}$ It is worth noting, however, the length of time (60 hours) between the completion of final exposure and the post IHE time trial. Furthermore, it is important to note that none of the aforementioned studies have then assessed the effectiveness of acclimation during an expedition to terrestrial altitude.

Studies comparing the use of IHE and IHT have typically reported no significant differences between groups in any physiological or performance variables, suggesting there is no additional benefit associated with exercising on exposure to hypoxia, even with an exercise-induced hypoxemia. ${ }^{104,105}$ Research is, however, limited on the extent to which the exercise stimulus has been explored, ie, time, intensity, and range of altitudes compared. There remains a sound physiological rationale that supports the hypothesis that there are benefits associated with the inclusion of exercise in hypoxic exposures. Even without significant physiological adaptations, a reduction in perceptual effort and familiarity with the level of exertion required to perform at altitude may reduce the psychological strain and impact of expeditions, thereby facilitating subsequent performance at terrestrial altitude. Given the requirement for sustained vigorous endurance exercise 
on high-altitude expeditions, more research is required to evaluate the potential benefits of IHT.

Presently, the research suggests that hypobaric hypoxia, in comparison to normobaric hypoxia, is more effective in stimulating acclimatization, ${ }^{96}$ which is consistent with that of terrestrial altitude exposure. IHE for $>1$ hour per day and $>4,000 \mathrm{~m}$ for a period of $1-3$ weeks increases peripheral capillary oxygen saturation $\left(\mathrm{SpO}_{2}\right)$, reduces symptoms of AMS, improves exercise performance, and reduces the physiological stress associated with high-altitude exposure. ${ }^{85,104}$ However, the optimal acclimation protocol is yet to be established, with more research required, particularly into the use of normobaric hypoxia, which is more easily accessible to a wider population.

\section{Inspiratory muscle training}

In addition to IHE and IHT, there are other potential techniques such as dietary nitrate supplementation (which has been discussed earlier) and inspiratory muscle training (IMT), which may attenuate arterial oxygen desaturation and a reduction in exercise performance during high-altitude exposure.

Acute exposure to hypoxia and the associated reduction in the arterial partial pressure of oxygen increases minute ventilation, in an attempt to normalize arterial oxygen saturation. However, this hyperventilation increases the work of breathing and in turn the demand for respiratory blood flow, ${ }^{107}$ making the respiratory muscles more susceptible to fatigue. This is likely to be further accentuated during exercise at altitude. Four weeks of IMT has been shown to reduce inspiratory muscle fatigue following exhaustive exercise by $\sim 10 \%$ in normobaric hypoxia $\left(\mathrm{FIO}_{2}=0.14\right.$, $\sim 3,050 \mathrm{~m}$ ), as well as attenuating the reduction in $\mathrm{SpO}_{2}$ by $\sim 5 \% .{ }^{108}$ The mechanism is not clearly defined, but the fact that IMT decreased cardiac output and increased lung diffusion capacity suggests that red blood cell transit time in the pulmonary capillary was prolonged. Further, dyspnea and rating of perceived exertion were reduced following exhaustive exercise. The latter may be important as the incidence of AMS has been shown to be higher following trekking days with high ratings of perceived exertion. ${ }^{73}$ Interestingly, reductions in arterial desaturation were not observed at rest, ${ }^{108}$ suggesting that the cardiopulmonary stress was not significant enough at $\sim 3,050 \mathrm{~m}$ in normobaric hypoxia. In contrast, 4 weeks of IMT only attenuated the reduction in $\mathrm{SpO}_{2}(6 \%)$ during rest at altitudes of $4,880 \mathrm{~m}$ and $5,550 \mathrm{~m}$ on a high-altitude expedition, suggesting an upper threshold for its effectiveness. ${ }^{109}$ Even though these studies show some promising findings, neither has assessed whether IMT can reduce an individual's susceptibility to AMS. Therefore, further research is required to establish whether IMT is an effective preexpedition strategy.

\section{Conclusion}

As the number of people traveling to altitude increases, the risk of life-threatening medical emergencies will also increase, and therefore, it is important that we have effective strategies to minimize their risk and accurately diagnose these conditions. Although the LLS was developed as a research tool, it is now widely used as a diagnostic tool for AMS. Several studies have questioned the validity of components of the LLS, such as headache and sleep, and suggested splitting the collection of symptoms known as AMS into separate conditions. Interest in biomarkers to predict the performance at altitude and risk of developing altitude disease has grown significantly. The use of BNP as a marker of PASP has been investigated considerably, and with further validation, studies may be an effective marker of HAPE. Interest in medications that may reduce the risk of altitude disease has expanded to nitrate supplementation and medications that propagate the effects of nitric oxide and to iron supplementation. The role of exercise in the development of altitude diseases remains hotly debated; current literature suggests that the intensity of exercise is more important than exercise itself. Finally, despite numerous studies suggesting that preacclimatization training may be helpful in reducing the risk of altitude illness, an optimal protocol for preacclimatization continues to be elusive. The science and medicine of altitude have developed significantly to the benefit of travelers and practitioners advising them; however, several key questions remain unanswered, and it is crucial that these are addressed so that we can advise travelers appropriately.

\section{Acknowledgment}

The authors thank O Shannon for his contribution to the "Nitrates" section.

\section{Disclosure}

The authors report no conflicts of interest in this work.

\section{References}

1. Shah NM, Windsor JS, Meijer J, Hillebrandt D. Are UK commercial expeditions complying with wilderness medical society guidelines on ascent rates to altitude? J Travel Med. 2011;18(3):214-216.

2. Montgomery AB, Mills J, Luce JM. Incidence of acute mountain sickness at intermediate altitude. JAMA. 1989;261(5):732-734. 
3. Chatre B, Lanzinger G, Macaluso M, et al. The Alps: People and Pressures in the Mountains, the Facts at a Glance. Innsbruck: Permanent Secretariat of the Alpine Convention; 2010.

4. West JB, Schoene RB, Luks AM, Milledge JS. High Altitude Medicine and Physiology. 5th ed. London: CRC Press; 2013.

5. Grocott MP, Martin DS, Levett DZ, et al. Arterial blood gases and oxygen content in climbers on Mount Everest. N Engl J Med. 2009;360(2): 140-149.

6. Hodkinson PD. Acute exposure to altitude. J R Army Med Corps. 2011; 157(1):85-91.

7. Karinen H, Peltonen J, Tikkanen H. Prevalence of acute mountain sickness among Finnish trekkers on Mount Kilimanjaro, Tanzania: an observational study. High Alt Med Biol. 2008;9(4):301-306.

8. Jackson SJ, Varley J, Sellers C, et al. Incidence and predictors of acute mountain sickness among trekkers on Mount Kilimanjaro. High Alt Med Biol. 2010;11(3):217-222.

9. Roach RC, Bartsch P, Hackett PH, Oelz O. The Lake Louise acute mountain sickness scoring system. In: Sutton JR, Houston CS, Coates G, editors. Hypoxia and Molecular Medicine. Burlington, VT: Queens City Printers; 1993:265-271.

10. Hall DP, MacCormick IJC, Phythian-Adams AT, et al. 2 Network analysis reveals distinct clinical syndromes underlying acute mountain sickness. PLoS One. 2014;9(1):e81229.

11. Hackett PH, Roach RC. High altitude illness. $N$ Engl J Med. 2001; 345(2):107-114.

12. Bartsch P, Mairbauri H, Maggiorini M, Swenson ER. Physiological aspects of high-altitude pulmonary edema. J Appl Physiol (1985). 2005;98(3):1101-1110.

13. Wilson $\mathrm{MH}$, Newman $\mathrm{S}$, Imray $\mathrm{CH}$. The cerebral effects of ascent to high altitudes. Lancet Neurol. 2009;8(2):175-191.

14. Lawley JS, Alperin N, Bagci AM, Lee SH, Mullins PG, Oliver SJ. Normobaric hypoxia and symptoms of acute mountain sickness: elevated brain volume and intracranial hypertension. Ann Neurol. 2014; 75(6):890-898.

15. Johnson C, Anderson SR, Dallimore J, Winser S, Warrell DA. Oxford Handbook of Expedition and Wilderness Medicine. London: Oxford University Press; 2008.

16. Luks AM, McIntosh SE, Grisson CK, Auerbach PS, Rodway GW, Schoene RB. Wilderness medical society practice guidelines for the prevention and treatment of acute altitude illness: 2014 update. Wilderness Environ Med. 2014;25(4 Suppl):S4-S14.

17. Pattenden HA, Shah NM, Hillebrandt D, Rodger M, Windsor JW. Do British commercial mountaineering expeditions carry drugs to treat high altitude illnesses? J Travel Med. 2012;19(4):250-252.

18. Burtscher M, Wille M, Menz V, Faulhaber M, Gatterer H. Symptom progression in acute mountain sickness during a 12-hour exposure to normobaric hypoxia equivalent to 4500-m. High Alt Med Biol. 2014; 15(4):446-451.

19. Ivan Lopez J, Holdridge A, Mendizabal JE. Altitude headache. Curr Pain Headache Rep. 2013;17(12):383.

20. Alizadeh R, Ziaee V, Aghsaeifard Z, Mehrabi F, Ahmadinejad T. Characteristics of headache at altitude among trekkers; a comparison between acute mountain sickness and non-acute mountain sickness headache. Asian J Sports Med. 2012;3(2):126-130.

21. Bian S-Z, Jin J, Li O-N, et al. Cerebral hemodynamic characteristics of acute mountain sickness upon acute high-altitude exposure at 3,700 m in young Chinese men. Eur J Appl Physiol. 2014;114(10): 2193-2200.

22. Roach R, Kayser B, Hackett P. Pro: headache should be a required symptom for the diagnosis of acute mountain sickness. High Alt Med Biol. 2011;12(1):21-22.

23. West JB. Con: headache should not be a required symptom for the diagnosis of acute mountain sickness. High Alt Med Biol. 2011;12(1): 23-25.

24. Karle FJ, Auerbach PS. Migraine headache confounding the diagnosis of acute mountain sickness. Wilderness Environ Med. 2014;25(1): $60-68$.
25. MacInnis MJ, Lanting SC, Rupert JL, Koehle MS. Is poor sleep quality at high altitude separate from acute mountain sickness? Factor structure and internal consistency of the Lake Louise Score Questionnaire. High Alt Med Biol. 2013;14(4):334-337.

26. Maisel A. B-type natriuretic peptide levels: diagnostic and prognostic in congestive heart failure: what's next? Circulation. 2002;105(20): 2328-2331.

27. Gatterer H, Wille M, Faulhaber M, et al. Association between body water status and acute mountain sickness. PLoS One. 2013;8(8):e73185.

28. Woods DR, Begley J, Stacey M, et al. Severe acute mountain sickness, brain natriuretic peptide and NT-proBNP in humans. Acta Physiol. 2012;205(3):349-355.

29. Woods DR, Mellor A, Begley J, et al. Brain natriuretic peptide and NT-proBNP levels reflect pulmonary artery systolic pressure in trekkers at high altitude. Physiol Res. 2013;62(6):597-603.

30. Mellor A, Boos C, Holdsworth D, et al. Cardiac biomarkers at high altitude. High Alt Med Biol. 2014;15(4):452-458.

31. Boos CJ, Holdsworth DA, Woods DR, Green K, Naylor J, Mellor A. Cardiac biomarkers and high altitude pulmonary edema. Int $J$ Cardiol. 2013;167(3):e65-e66.

32. Gao M, Wang R, Jiayong Z, Liu Y, Sun G. NT-ProBNP levels are moderately increased in acute high-altitude pulmonary edema. Exp Ther Med. 2013;5(5):1434-1438.

33. Tannheimer M, Hornung K, Gasche M, et al. Decrease of asymmetric dimethylarginine predicts acute mountain sickness. J Trav Med. 2012; 19(6):338-343.

34. Mellor A, Boos C, Stacey M, et al. Neutrophil gelatinase-associated lipocalin: its response to hypoxia and association with acute mountain sickness. Dis Markers. 2013;35(5):537-542.

35. Tannheimer M, Biggel K, Engelhardt M, Benesch S, Schmidt R. Quantifying altitude related oxidative stress by carbonyl proteins. Med Sportiva. 2012;16(2):70-72.

36. Julian CG, Subudhi AW, Hill RC, et al. Exploratory proteomic analysis of hypobaric hypoxia and acute mountain sickness in humans. J Appl Physiol. 2014;116(7):937-944.

37. Ahmad Y, Sharma NK, Ahmad MF, Sharma M, Garg I, Bhargava K. Proteomic identification of novel differentiation plasma protein markers in hypobaric hypoxia-induced rat model. PLoS One. 2014;9(5):e98027.

38. Leaf DE, Goldfarb DS. Mechanisms of action of acetazolamide in the prophylaxis and treatment of acute mountain sickness. J Appl Physiol (1985). 2007;102(4):1313-1322.

39. Deshwal R, Iqbal M, Basnet $\mathrm{S}$. Nifedipine for the treatment of high altitude pulmonary edema. Wilderness Environ Med. 2012;23(1):7-10.

40. Sanchez del Rio M, Moskowitz MA. High altitude headache. Lessons from headaches at sea level. Adv Exp Med Biol. 1999;474:145-153.

41. Hartmann G, Tschöp M, Fischer R. High altitude increases circulating interleukin-6, interleukin-1 receptor antagonist, and C-reactive protein. Cytokine. 2000;12(3):246-252.

42. Kayser B, Hulsebosch R, Bosch F. Low-dose acetylsalicylic acid analog and acetazolamide for prevention of acute mountain sickness. High Alt Med Biol. 2008;9(1):15-23.

43. Gertsch JH, Corbett B, Holck PS, et al. Altitude sickness in climbers and efficacy of NSAIDs trial (ASCENT): randomized, controlled trial of ibuprofen versus placebo for prevention of altitude illness. Wilderness Environ Med. 2012;23(4):307-315.

44. Lipman GS, Kanaan NC, Holck PS, Constance BB, Gertsch JH; PAINS Group. Ibuprofen prevents altitude illness: a randomized controlled trial for prevention of altitude illness with nonsteroidal anti-inflammatories. Ann Emerg Med. 2012;59(6):484-490.

45. Pandit A, Karmacharya P, Pathak R, Giri S, Aryal MR. Efficacy of NSAIDs for the prevention of acute mountain sickness: a systematic review and meta-analysis. J Community Hosp Intern Med Perspect. 2014;29(4):4.

46. Gertsch JH, Lipman GS, Holck PS, et al. Prospective, double-blind, randomized, placebo-controlled comparison of acetazolamide versus ibuprofen for prophylaxis against high altitude headache: the headache evaluation at altitude trial (HEAT). Wilderness Environ Med. 2010; 21(3):236-243. 
47. Droma Y, Hanaoka M, Ota M, et al. Positive association of the endothelial nitric oxide synthase gene polymorphisms with high-altitude pulmonary edema. Circulation. 2002;106(7):826-830.

48. Levett DZ, Fernandez BO, Riley HL, et al. The role of nitrogen oxides in human adaptation to hypoxia. Sci Rep. 2011;1:109.

49. Erzurum SC, Ghosh S, Janocha AJ, et al. Higher blood flow and circulating NO products offset high-altitude hypoxia among Tibetans. Proc Natl Acad Sci U S A. 2007;104(45):17593-17598.

50. Beall CM, Laskowski D, Strohl KP, et al. Pulmonary nitric oxide in mountain dwellers. Nature. 2001;414(6862):411-412.

51. Wylie LJ, Kelly J, Bailey SJ, et al. Beetroot juice and exercise: pharmacodynamic and dose-response relationships. J Appl Physiol (1985). 2013;115(3):325-336.

52. Larsen FJ, Weitzberg E, Lundberg JO, Ekblom B. Effects of dietary nitrate on oxygen cost during exercise. Acta Physiol. 2007;191(1) 59-66.

53. Masschelein E, Van Thienen R, Wang X, Van Schepdael A, Thomis M, Hespel P. Dietary nitrate improves muscle but not cerebral oxygenation status during exercise in hypoxia. J Appl Physiol (1985). 2012;113(5): 736-745.

54. Vanhatalo A, Fulford J, Bailey SJ, Blackwell JR, Winyard PG, Jones AM. Dietary nitrate reduces muscle metabolic perturbation and improves exercise tolerance in hypoxia. J Physiol. 2011;589(pt 22) 5517-5528.

55. Kelly J, Vanhatalo A, Bailey SJ, et al. Dietary nitrate supplementation: effects on plasma nitrite and pulmonary $\mathrm{O} 2$ uptake dynamics during exercise in hypoxia and normoxia. Am J Physiol Regul Integr Comp Physiol. 2014;307(7):R920-R930.

56. Muggeridge DJ, Howe CC, Spendiff O, et al. The effects of a single dose of concentrated beetroot juice on performance in trained flatwater kayakers. Int J Sport Nutr Exer Metab. 2013;23(5):498-506.

57. Vanhatalo A, Jones AM, Blackwell JR, Winyard PG, Fulford J. Dietary nitrate accelerates postexercise muscle metabolic recovery and $\mathrm{O} 2$ delivery in hypoxia. J Appl Physiol. 2014;117(12):1460-1470.

58. Larsen FJ, Schiffer TA, Borniquel S, et al. Dietary inorganic nitrate improves mitochondrial efficiency in humans. Cell Metab. 2011;13(2): 149-159.

59. Bailey SJ, Fulford J, Vanhatalo A, et al. Dietary nitrate supplementation enhances muscle contractile efficiency during knee-extensor exercise in humans. J Appl Physiol (1985). 2010;109(1):135-148.

60. Ferguson SK, Hirai DM, Copp SW, et al. Impact of dietary nitrate supplementation via beetroot juice on exercising muscle vascular control in rats. J Physiol. 2013;591(2):547-557.

61. Baumgartner RW, Bärtsch P, Maggiorini M, Waber U, Oelz O. Enhanced cerebral blood flow in acute mountain sickness. Aviat Space Environ Med. 1994;65(8):726-729.

62. Ghofrani HA, Reichenberger F, Kohstall MG, et al. Sildenafil increased exercise capacity during hypoxia at low altitudes and at Mount Everest base camp: a randomized, double-blind, placebo-controlled crossover trial. Ann Intern Med. 2004;141(3):169-177.

63. Jacobs KA, Kressler J, Stoutenberg M, Roos BA, Friedlander AL. Sildenafil has little influence on cardiovascular hemodynamics or 6-km time trial performance in trained men and women at simulated high altitude. High Alt Med Biol. 2011;12(3):215-222.

64. Olfert IM, Loeckinger A, Treml B, et al. Sildenafil and bosentan improve arterial oxygenation during acute hypoxic exercise: a controlled laboratory trial. Wilderness Environ Med. 2011;22(3):211-221.

65. Bates MG, Thompson AA, Baillie JK, et al. Sildenafil citrate for the prevention of high altitude hypoxic pulmonary hypertension: double blind, randomized, placebo-controlled trial. High Alt Med Biol. 2011;12(3): 207-214.

66. Smith TG, Balanos GM, Croft QP, et al. The increase in pulmonary arterial pressure caused by hypoxia depends on iron status. J Physiol. 2008;586(pt 24):5999-6005

67. Smith TG, Talbot NP, Privat C, et al. Effects of iron supplementation and depletion on hypoxic pulmonary hypertension: two randomized controlled trials. JAMA. 2009;302(13):1444-1450.
68. Epstein AC, Gleadle JM, McNeill LA, et al. C. elegans EGL-9 and mammalian homologs define a family of dioxygenases that regulate HIF by prolyl hydroxylation. Cell. 2001;107(1):43-54.

69. Knowles HJ, Raval RR, Harris AL, Ratcliffe PJ. Effect of ascorbate on the activity of hypoxia-inducible factor in cancer cells. Cancer Res. 2003;63(8):1764-1768.

70. Talbot NP, Smith TG, Privat C, et al. Intravenous iron supplementation may protect against acute mountain sickness: a randomized, doubleblinded, placebo-controlled trial. High Alt Med Biol. 2011;12(3): 265-269.

71. Roach RC, Maes D, Sandoval D, et al. Exercise exacerbates acute mountain sickness at simulated high altitude. J Appl Physiol (1985). 2000;88(2):581-585.

72. Edsell M, Wimalasena Y, Malein W, et al. High-intensity intermittent exercise increases pulmonary interstitial edema at altitude but not at simulated altitude. Wilderness Environ Med. 2014;25(4):409-415.

73. Mellor A, Woods D, O'Hara J, Howley M, Watchorn J, Boos C. Rating of perceived exertion and acute mountain sickness during a high-altitude trek. Aviat Space Environ Med. 2014;85(12):1214-1216.

74. Rupp T, Jubeau M, Millet G, et al. The effect of hypoxemia and exercise on acute mountain sickness symptoms. J Appl Physiol (1985). 2012; 114(2):180-185

75. Mairer K, Wille M, Grander W, Burtscher M. Effects of exercise and hypoxia on heart rate variability and acute mountain sickness. Int J Sports Med. 2013;34(08):700-706.

76. Rupp T, Jubeau M, Lamalle L, et al. Cerebral volumetric changes induced by prolonged hypoxic exposure and whole-body exercise. J Cereb Blood Flow Metab. 2014;34(11):1802-1809.

77. SelfDA, Mandella JG, Prinzo OV, Forster EM, Shaffstall RM. Physiological equivalence of normobaric and hypobaric exposures of humans to 25,000 feet (7620 m). Aviat Space Environ Med. 2011;82(2):97-103.

78. Woods DR, Davison A, Stacey M, et al. The cortisol response to hypobaric hypoxia at rest and post-exercise. Horm Metab Res. 2012;44(4): 302-305.

79. Sanavi S, Mirsepasi M. Serum cortisol and testosterone alterations following exercise in normoxic and hypoxic conditions in trained young men. Saudi J Sports Med. 2013;13(1):27-33.

80. Mellor AJ, Boos CJ, Ball S, et al. Copeptin and arginine vasopressin at high altitude: relationship to plasma osmolality and perceived exertion. Eur J Appl Physiol. 2015;115(1):91-98.

81. Kallenberg K, Bailey DM, Christ S, et al. Magnetic resonance imaging evidence of cytotoxic cerebral edema in acute mountain sickness. J Cereb Blood Flow. 2007;27(5):1064-1071.

82. Schoonman GG, Sandor PS, Nirkko AC, et al. Hypoxia-induced acute mountain sickness is associated with intracellular cerebral edema: a 3 T magnetic resonance imaging study. J Cereb Blood Flow Metab. 2008;28(1):198-206.

83. Debevec T, Pialoux V, Mekjavic I, Eiken O, Mury P, Millet G. Moderate exercise blunts oxidative stress induced by normobaric hypoxic confinement. Med Sci Sports Exerc. 2014;46(1):33-41.

84. Muza SR, Beidleman BA, Fulco CS. Altitude preexposure recommendations for inducing acclimatisation. High Alt Med Biol. 2010;11(2): 87-92.

85. Beidleman BA, Muza SR, Fulco CS, et al. Intermittent altitude exposures reduce acute mountain sickness at $4300 \mathrm{~m}$. Clin Sci (Lond). 2004;106(3):321-328.

86. Beidleman BA, Fulco CS, Muza SR, et al. Effect of six days of staging on physiologic adjustments and acute mountain sickness during ascent to 4300 meters. High Alt Med Biol. 2009;10(3):253-260.

87. Fulco CS, Muza SR, Beidleman B, et al. Exercise performance of sea level residents at $4300 \mathrm{~m}$ after 6 days at $2200 \mathrm{~m}$. Aviat Space Environ Med. 2009;80(11):955-961.

88. Savourey G, Garcia N, Besnard Y, Hanniquet AM, Fine MO, Bittel J. Physiological changes induced by pre-adaptation to high altitude. Eur J Appl Physiol Occup Physiol. 1994;69(3):221-227.

89. Wilber RL. Application of altitude, hypoxic training by elite athletes. J Hum Sport Exerc. 2011;6(2):271-286. 
90. Richalet JP, Bittel J, Herry JP, et al. Use of hypobaric chamber for pre-acclimatization before climbing Mount Everest. Int J Sports Med. 1992;13(Suppl 1):S216-S220.

91. Nagasaka T, Satake T. Changes of pulmonary and cardiovascular functions in subjects confined intermittently in a low pressure chamber for 3 consecutive days. Fed Proc. 1969;28(3):1312-1315.

92. Savourey G, Garcia N, Benard Y, Guinet A, Hanniquet AM, Bittel J. Pre-adaptation, adaptation and de-adaptation to high altitude in humans: cardio-ventilatory and hematological changes. Eur J Appl Physiol Occup Physiol. 1996;73(6):529-535.

93. Rodriguez FA, Casas H, Casas M, et al. Intermittent hypobaric hypoxia stimulates erythropoiesis and improves aerobic capacity. Aviat Space Environ Med. 1999;31(2):264-268.

94. Rodriguez FA, Ventura JL, Casas M, et al. Erythropoietin acute reaction and hematological adaptations to short, intermittent hypobaric hypoxia. Eur J Appl Physiol. 2000;82(3):170-177.

95. Casas M, Casas H, Pagés T, et al. Intermittent hypobaric hypoxia induces altitude acclimation and improves the lactate threshold. Aviat Space Environ Med. 2000;71(2):125-130.

96. Fulco CS, Beidleman B, Muza SR. Effectiveness of preacclimatisation strategies for high altitude exposure. Exerc Sport Sci Rev. 2013;41(1): 55-63.

97. Coppel J, Hennis P, Gilbert-Kawai E, Grocott MP. The physiological effects of hypobaric hypoxia versus normobaric hypoxia: a systematic review of crossover trials. Extreme Physiol Med. 2015; 4(2): 1-20.

98. Millet GP, Faiss R, Pialoux V. Evidence for differences between hypobaric and normobaric hypoxia is conclusive. Exerc Sport Sci Rev. 2013;41(2):133.

99. Garcia N, Hopkins SR, Powell FL. Effects of intermittent hypoxia on the isocapnic hypoxic ventilatory response and erythropoiesis in humans. Respir Physiol. 2000;123(1-2):39-49.
100. Katayama K, Sato K, Hotta N, Ishida K, Iwasaki K, Miyamura M. Intermittent hypoxia does not increase exercise ventilation at simulated moderate altitude. Int J Sports Med. 2007;28(6):480-487.

101. Katayama K, Koji I, Ken-ichi I, Miharu M. Effect of two durations of short-term intermittent hypoxia on ventilatory chemosensitivity in humans. Eur J Appl Physiol. 2009;105(5):815-821.

102. Katayama K, Sato Y, Ishida K, Mori S, Miyamura M. The effects of intermittent exposure to hypoxia during endurance exercise training on the ventilatory responses to hypoxia and hypercapnia in humans. Eur J Appl Physiol Occup Physiol. 1998;78(3):189-114.

103. Levine BD, Friedman DB, Engfred K, et al. The effect of normoxic or hypobaric hypoxic endurance training on the hypoxic ventilatory response. Med Sci Sports Exerc. 1992;24(7):769-775.

104. Beidleman BA, Muza SR, Fulco CS, et al. Intermittent altitude exposures improve muscular performance at $4300 \mathrm{~m}$. J Appl Physiol (1985). 2003;95(5):1824-1832.

105. Beidleman BA, Muza SR, Fulco CS, et al. Intermittent hypoxic exposure does not improve endurance performance at altitude. Med Sci Sports Exerc. 2009;41(6):1317-1325.

106. Beidleman BA, Muza SR, Fulco CS, et al. Seven intermittent exposures to altitude improves exercise performance at $4300 \mathrm{~m}$. Med Sci Sports Exerc. 2008;40(1):141-148.

107. Guenetee JA, Sheel AW. Physiological consequences of a high altitude work of breathing during heavy exercise in humans. J Sci Med Sport. 2007; 10(6):341-350.

108. Downey AE, Chenoweth LM, Townsend DK, Ranum JD, Ferguson CS, Harms CS. Effects of Inspiratory muscle training on exercise responses in normoxia and hypoxia. Respir Physiol Neurobiol. 2007;156(2): 137-146.

109. Lomax M. Inspiratory muscle training, altitude, and arterial oxygen desaturation: a preliminary investigation. Aviat Space Environ Med. 2010;81(5):498-501.
Open Access Journal of Sports Medicine

\section{Publish your work in this journal}

Open Access Journal of Sports Medicine is an international, peer-reviewed, open access journal publishing original research, reports, reviews and commentaries on all areas of sports medicine. The manuscript management system is completely online and includes a very quick and fair peer-review system.

\section{Dovepress}

Visit http://www.dovepress.com/testimonials.php to read real quotes from published authors. 